\title{
PENGARUH SHIFT KERJA TERHADAP KINERJA MELALUI VARIABEL KELELAHAN DAN BEBAN KERJA SEBAGAI VARIABEL INTERVENING DI PT M.I
}

\author{
Dony Arianto'1, Asri Dwi Puspita² \\ e-mail : donyarianto01@gmail.com, asripuspita85@dosen.umaha.ac.id \\ Teknik Industri, Fakultas Teknik \\ Universitas Maarif Hasyim Latif, Sidoarjo, Indonesia
}

\begin{abstract}
ABSTRAK
Semua perusahaan pasti ingin memiliki karyawan dengan kinerja yang tinggi, begitu pula dengan PT M.I Kinerja karyawan yang baik akan ditunjukkan dengan adanya prestasi kerja baik secara kualitas maupun kuantitas. Kinerja yang baik di pengaruhi oleh beberapa faktor seperti Beban kerja, Kelelahan kerja dan Shift Kerja yang di atur dan di jalankan dengan baik. Dalam rangka Peningkatan kinerja inilah PT M.I perlu untuk mengetahui Faktor mana sajakah yang Paling berpengaruh dan dominan dalam pencapaian Kinerja yang baik. Penelitian ini lebih bersifat deskriptif yang berfokus pada analisis korelasi dengan penggunaan metode Structural Equation Modeling (SEM) dengan tools SmartPLS sebagai alat yang diharapkan dapat membantu PT M.I dalam menganalisis hasil dan menentukan strategi yang akan di lakukan demi meningkatkan kinerja karyawannya. Pengumpulan data yang dilakukan dalam penelitian ini adalah menggunakan metode kuisioner dan dokumentasi. Berdasarkan hasil analisis menggunakan Structural Equation Modeling (SEM) maka diketahui bahwa variabel Shift kerja berpengaruh positif dan signifikan terhadap beban dan kelelahan kerja yang berdampak terhadap penurunan kinerja karyawan. Hasil dari penelitian ini tentunya bisa digunakan sebagai acuan oleh PT M.I dalam meningkatkan kinerja karyawannya pada masa yang akan datang.
\end{abstract}

\section{Kata Kunci : Shift Kerja, Kelelahan Kerja, Beban Kerja, Kinerja, SmartPLS.}

\section{PENDAHULUAN}

Permintaan pasar yang tinggi akan suatu produk membuat perusahaan harus melakukan berbagai cara untuk memenuhi tuntutan tersebut. karena semakin banyak penjualan produk maka hasil atau untung yang didapatkan tentunya juga semakin banyak maka tak jarang perusahaan harus beroperasi penuh selama 24 jam non - stop demi memenuhi target produksi dan permintaan pasar yang tinggi. Tuntutan efisiensi dan demi meminimalkan cost maka perusahaan harus bijak dalam mengelola sumber daya manusia yang ada, semakin tingginya tuntutan gaji karyawan membuat perusahaan harus meminimalkan jumlah pekerja yang digunakan.

Menerapkan sistem kerja secara shift adalah cara yang paling sesuai diterapkan bagi perusahaan yang menjalankan produksinya secara penuh selama 24 jam non - stop. Cara ini dilakukan karena perusahaan diuntungkan dengan tetap dapat menjalankan produksinya secara penuh dan dapat meminimalkan jumlah pekerja yang dipakai. Cara ini memang menguntungkan bagi perusahaan tetapi juga mempunyai dampak yang tidak baik bagi pekerja yang terlibat di dalam sistem kerja shift, karena sistem kerja shift dapat menimbulkan beban kerja, kelelahan serta menurunya kinerja pada pegawai. Hal ini disebabkan karena didalam sistem kerja secara shift pekerja dituntut harus bisa beradaptasi dengan pembagian waktu kerja secara rotasi pagi, siang dan malam, jam kerja yang tidak teratur serta waktu kerja yang panjang.

Sistem shift kerja biasanya dibagi 3 macam yaitu sistem kerja 2 shift adalah waktu kerja yang terbagi menjadi 2 bagian waktu yaitu pagi dan sore yang dimulai pukul $(07.00-15.00)$ dan pukul (15.00 - 23.00), sistem kerja 3 shift adalah waktu kerja yang terbagi menjadi 3 bagian waktu yaitu pagi, sore dan malam hari dimulai pukul (07.00 15.00), (15.00 - 23.00) dan (23.00 - 07.00) yang ketiga adalah sistem non shift atau normal yaitu waktu kerja yang dilakukan hanya pada pagi sampai sore hari saja dimulai pukul (08.00 16.00).

Berdasarkan dari latar belakang diatas penelitian ini dilakukan untuk mengetahui seberapa besar pengaruh variabel shift kerja terhadap variabel kelelahan, variabel beban kerja terhadap variabel kinerja pada karyawan PT.MI pada bagian produksi dan variabel manakah yang paling dominan berpengaruh terhadap kinerja karyawan PT.MI pada bagian produksi. 


\section{METODE PENELITIAN}

Metode dalam penelitian ini yang pertama adalah menentukan jumlah sampel dari total populasi yang diambil untuk menentukan jumlah kuesioner yang akan diberikan kepada responden, kemudian uji validitas dan reliabilitas kuesioner setelah dinyatakan valid dan reliabel lanjut ke tahap pengolahan data menggunakan SmartPLS kemudian diambil kesimpulan. Jumlah populasi dari penelitian ini adalah 135 responden dan sampel yang diambil dari penelitian ini berjumlah 100 responden berdasarkan perhitungan rumus slovin.

Uji validitas dan reliabilitas diperlukan untuk menguji valid atau tidaknya data dari hasil rekapitulasi kuesioner dengan software SPSS. Setelah semua data dari hasil rekapitulasi kuesioner dinyatakan valid dan reliabel maka dilanjutkan dengan metode analisis data menggunakan SmartPLS.

\section{HASIL DAN PEMBAHASAN}

\section{Perumusan Hipotesis}

H1 : Shift kerja berpengaruh positif dan signifikan terhadap kelelahan kerja.

H2 : Shift kerja berpengaruh positif dan signifikan terhadap beban kerja.

H3 : Kelelahan kerja berpengaruh positif dan signifikan terhadap kinerja.

H4 : Beban kerja berpengaruh positif dan signifikan terhadap kinerja.

H5 : Shift kerja berpengaruh positif dan signifikan terhadap kinerja

\section{Kategori Jenis Kelamin Responden}

Tabel 1. Jenis Kelamin

\begin{tabular}{|c|c|c|}
\hline Jenis Kelamin & Jumlah & Prosentase(\%) \\
\hline Pria & 52 & 52 \\
\hline Wanita & 48 & 48 \\
\hline Total & 100 & 100 \\
\hline
\end{tabular}

Sumber : Data Kuesioner

Dari tabel di atas dapat diketahui yang menjadi responden paling banyak adalah berjenis laki - laki yaitu berjumlah $52.0 \%$ sedangkan responden perempuan berjumlah $48.0 \%$. Dengan jumlah total responden $100 \%$

\section{Kategori Usia Responden}

Tabel 2. Usia Responden

\begin{tabular}{|c|c|c|}
\hline Umur & Jumlah & Prosentase (\%) \\
\hline 25 & 2 & 2 \\
\hline 26 & 1 & 1 \\
\hline
\end{tabular}

\begin{tabular}{|c|c|c|}
\hline 28 & 9 & 9 \\
\hline 29 & 6 & 6 \\
\hline 30 & 12 & 12 \\
\hline 31 & 1 & 1 \\
\hline 32 & 15 & 15 \\
\hline 33 & 6 & 6 \\
\hline 34 & 15 & 15 \\
\hline 35 & 9 & 9 \\
\hline 36 & 11 & 11 \\
\hline 38 & 4 & 4 \\
\hline 40 & 8 & 8 \\
\hline 42 & 1 & 1 \\
\hline Total & 100 & 100 \\
\hline
\end{tabular}

Sumber : Data Kuesioner

Dari tabel diatas menunjukan bahwa responden dengan usia 20 - 25 tahun keatas sebanyak 2 orang (2\%), responden dengan usia 25 - 30 tahun sebanyak 28 orang (28\%), responden dengan usia 30 - 35 tahun sebanyak 46 orang (46\%), responden dengan usia 35 - 40 tahun sebanyak 23 orang (23\%), dan responden dengan usia $40>$ sebanyak 1 orang (1\%). Dalam hal ini menunjukan bahwa mayoritas responden dalam penelitian ini berusia antara $30-35$

\section{Kategori Masa Kerja Responden}

Tabel 3. Masa Kerja

\begin{tabular}{|c|c|c|}
\hline Masa Kerja & Jumlah & Prosentase (\%) \\
\hline 10 & 10 & 10 \\
\hline 11 & 5 & 5 \\
\hline 12 & 14 & 14 \\
\hline 13 & 6 & 6 \\
\hline 14 & 4 & 4 \\
\hline 15 & 5 & 5 \\
\hline 16 & 4 & 4 \\
\hline 18 & 4 & 4 \\
\hline 20 & 1 & 1 \\
\hline 21 & 1 & 1 \\
\hline 22 & 1 & 1 \\
\hline 23 & 1 & 1 \\
\hline 5 & 4 & 4 \\
\hline 6 & 10 & 10 \\
\hline 7 & 6 & 6 \\
\hline 8 & 14 & 14 \\
\hline 9 & 10 & 10 \\
\hline Total & 100 & 100 \\
\hline
\end{tabular}

Sumber: Data Kuesioner 
Dari tabel masa kerja di atas dapat diketahui bahwa responden yang mempunyai masa kerja 10 tahun sebanyak 10 orang (10\%), masa kerja 11 tahun sebanyak 5 orang (\%), masa kerja 12 tahun sebanyak 14 orang (5\%), masa kerja 13 tahun sebanyak 6 orang (\%), masa kerja 14 tahun sebanyak 4 orang (4\%), masa kerja 15 tahun sebanyak 5 orang (\%), masa kerja 16 tahun sebanyak 4 orang (\%), masa kerja 18 tahun sebanyak 4 orang (4\%), masa kerja 20 tahun sebanyak 1 orang (1\%), masa kerja 21 tahun sebanyak 1 orang (1\%), masa kerja 22 tahun sebanyak 1 orang (1\%), masa kerja 23 tahun sebanyak 1 orang (1\%), masa kerja 5 tahun sebanyak 4 orang (4\%), masa kerja 6 tahun sebanyak 10 orang (10\%), masa kerja 7 tahun sebanyak 6 orang (6\%), masa kerja 8 tahun sebanyak 14 orang (14\%), masa kerja 9 tahun sebanyak 10 orang (10\%).

\section{Kategori Pendidikan Terakhir Responden}

Tabel 4. Pendidikan Terahir

\begin{tabular}{|c|c|c|}
\hline Pendidikan Terahir & Jumlah & Prosentase (\%) \\
\hline Sarjana & 7 & 7 \\
\hline SMA & 58 & 8 \\
\hline SMK & 35 & 55 \\
\hline Total & 100 & 100 \\
\hline
\end{tabular}

Sumber : Data Kuesioner

Dari tabel diatas menunjukan bahwa tingkat pendidikan responden dengan tingkat SMK sebanyak 35 orang (35\%), responden dengan tingkat SMA sebanyak 58 orang (58\%), responden dengan pendidikan SARJANA sebanyak 7 orang (7\%), dari data penelitian ini berarti mayoritas pendidikan responden yang paling mendominasi adalah tingkat SMA yaitu sebanyak 58 orang (58\%), kemudian tingkat SMK yaitu sebanyak 35 orang (35\%), kemudian terahir tingkat SARJANA yaitu sebanyak 7 orang (7\%).

\section{Pemodelan Structusral Equation Modeling (SEM)}

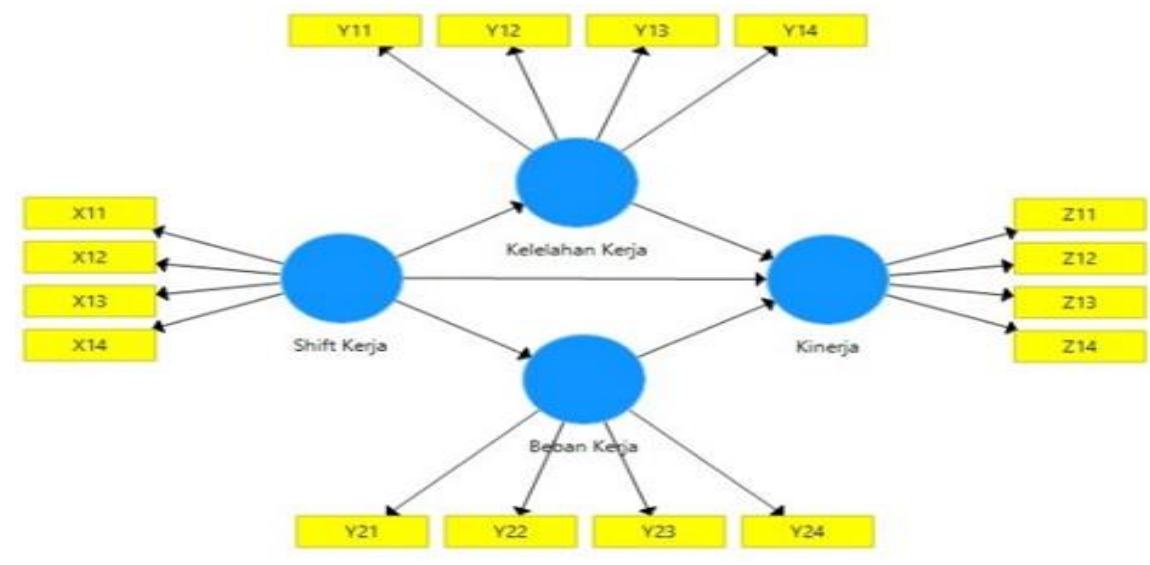

Gambar 1. Perancangan Model Penelitian

\section{Uji Validitas Outer Loadings (Measurement Model)}

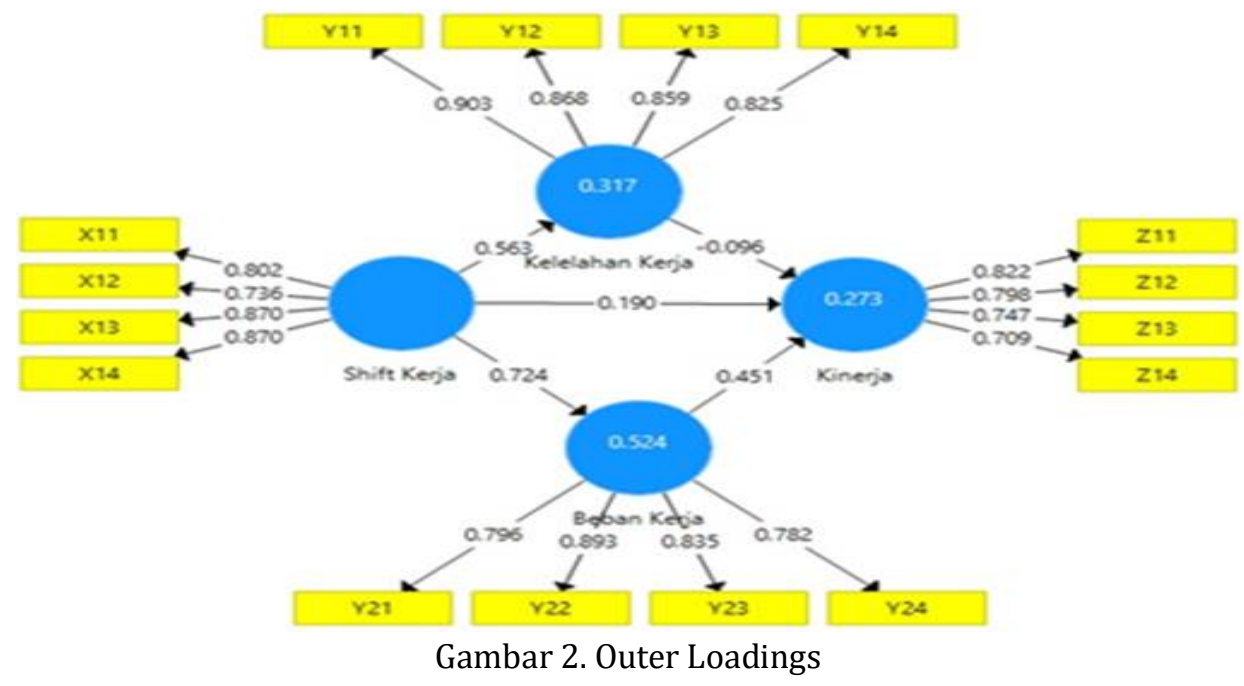


Tabel 5. Outer Loading (Measurement Model)

\begin{tabular}{|c|c|c|}
\hline Indikator & Nilai Loading & Keterangan \\
\hline \multicolumn{3}{|c|}{ Shift Kerja } \\
\hline X1.1 & 0.802 & Valid \\
\hline X1.2 & 0.736 & Valid \\
\hline X1.3 & 0.87 & Valid \\
\hline X1.4 & 0.87 & Valid \\
\hline \multicolumn{3}{|c|}{ Kelelahan Kerja } \\
\hline Y1.1 & 0.903 & Valid \\
\hline Y1.2 & 0.868 & Valid \\
\hline Y1.3 & 0.859 & Valid \\
\hline Y1.4 & 0.825 & Valid \\
\hline \multicolumn{3}{|c|}{ Beban Kerja } \\
\hline Y2.1 & 0.796 & Valid \\
\hline Y2.2 & 0.893 & Valid \\
\hline Y2.3 & 0.835 & Valid \\
\hline Y2.4 & 0.782 & Valid \\
\hline \multicolumn{2}{|c|}{ Kinerja } \\
\hline Z1.1 & 0.822 & Valid \\
\hline Z1.2 & 0.798 & Valid \\
\hline Z1.3 & 0.747 & Valid \\
\hline Z1.4 & 0.709 &
\end{tabular}

Sumber: Output data primer yang di olah.

Tabel 6. Hasil discriminant validity

\begin{tabular}{|c|c|c|c|c|c|}
\hline Indikator & Shift Kerja & Kelelahan & Beban & Kinerja & Ket \\
\hline X1.1 & 0.802 & 0.425 & 0.499 & 0.305 & Valid \\
\hline $\mathrm{X} 1.2$ & 0.736 & 0.393 & 0.425 & 0.397 & Valid \\
\hline $\mathrm{X} 1.3$ & 0.87 & 0.477 & 0.609 & 0.349 & Valid \\
\hline $\mathrm{X} 1.4$ & 0.87 & 0.534 & 0.759 & 0.454 & Valid \\
\hline Y1.1 & 0.554 & 0.903 & 0.893 & 0.453 & Valid \\
\hline Y1.2 & 0.503 & 0.869 & 0.823 & 0.44 & Valid \\
\hline Y1.3 & 0.394 & 0.859 & 0.745 & 0.334 & Valid \\
\hline Y1.4 & 0.473 & 0.825 & 0.707 & 0.203 & Valid \\
\hline Y2.1 & 0.836 & 0.543 & 0.796 & 0.43 & Valid \\
\hline Y2.2 & 0.554 & 0.903 & 0.893 & 0.453 & Valid \\
\hline Y2.3 & 0.483 & 0.865 & 0.835 & 0.424 & Valid \\
\hline Y2.4 & 0.358 & 0.865 & 0.782 & 0.308 & Valid \\
\hline $\mathrm{Z1.1}$ & 0.392 & 0.331 & 0.396 & 0.822 & Valid \\
\hline $\mathrm{Z} 1.2$ & 0.408 & 0.275 & 0.356 & 0.796 & Valid \\
\hline $\mathrm{Z} 1.3$ & 0.267 & 0.397 & 0.428 & 0.747 & Valid \\
\hline Z1.4 & 0.356 & 0.32 & 0.362 & 0.709 & Valid \\
\hline
\end{tabular}

Sumber : Output data primer yang di olah 
Dari hasil uji validitas Outer Loading pada tabel 5 di atas dapat dilihat bahwa semua nilai Outer Loading Reflektif diatas 0.7 sehingga indikator - indikator yang dipergunakan dalam penelitian ini telah memenuhi validitas konvergen (Convergent Validity).

Dari hasil uji validitas cross loading pada tabel 6 diatas dapat dilihat bahwa semua nilai cross loading mempunyai nilai tertinggi terhadap konstruk yang dituju dibandingkan nilai cross loading factor kepada konstruk lain.

\section{Composite Reliability}

Tabel 7. Nilai Composite Reliability.

\begin{tabular}{|l|l|l|}
\hline Variabel & $\begin{array}{l}\text { Composite } \\
\text { Reliability }\end{array}$ & Keterangan \\
\hline Shift Kerja (X1) & 0.862 & Reliabel \\
\hline Kelelahan Kerja (Y1) & 0.922 & Reliabel \\
\hline Beban Kerja (Y2) & 0.896 & Reliabel \\
\hline Kinerja (Z1) & 0.853 & Reliabel \\
\hline
\end{tabular}

Sumber : Output data primer yang di olah.
Berdasarkan tabel diatas dapat disimpulkan bahwa semua konstruk memenuhi kriteria reliabel. Hal ini ditunjukan dengan nilai composite reliability diatas 0.70 sebagaimana kriteria yang direkomendasikan.

\section{R-Square}

Tabel 8. Nilai $R$-Square

\begin{tabular}{|l|c|}
\hline \multicolumn{1}{|c|}{ Variabel } & R-Square \\
\hline Kelelahan Kerja (Y1) & 0.317 \\
\hline Beban Kerja (Y2) & 0.524 \\
\hline Kinerja (Z1) & 0.273 \\
\hline Shift Kerja (X1) & \\
\hline
\end{tabular}

Sumber : Output data primer yang di olah.

R-square bernilai antara 0 - 1 dengan ketentuan semakin angka mendekati 1 berarti semakin baik. Jika R-Square bernilai 0.6 berarti $60 \%$ sebaran variabel dependen dapat dijelaskan oleh variabel independen. Sisanya 40\% tidak dapat dijelaskan oleh variabel diluar variabel independen (komponen error).

\section{Uji Tabel T}

Tabel 9. Hasil Perhitungan Bootstraping Data Penelitian

\begin{tabular}{|l|l|l|l|r|}
\hline \multicolumn{1}{|c|}{ Variabel } & \multicolumn{1}{|c|}{$\begin{array}{c}\text { Original Sample } \\
\text { Estimate }\end{array}$} & $\begin{array}{c}\text { Mean Of Sub } \\
\text { samples }\end{array}$ & \multicolumn{1}{c|}{$\begin{array}{c}\text { Standard } \\
\text { Deviation }\end{array}$} & T-Statictic \\
\hline Shift Kerja (X1) -> Kelelahan Kerja (Y1) & 0.563 & 0.572 & 0.071 & 7.986 \\
\hline Shift Kerja (X1) -> Beban Kerja(Y2) & 0.724 & 0.733 & 0.047 & 15.473 \\
\hline Shift Kerja (X1) -> Kinerja (Z1) & 0.19 & 0.144 & 0.203 & 939 \\
\hline Kelelahan Kerja (Y1) -> Kinerja (Z1) & -0.096 & -0.168 & 0.325 & 0.295 \\
\hline Beban Kerja (Y2) -> Kinerja (Z1) & 0.451 & 0.568 & 0.44 & 1.026 \\
\hline
\end{tabular}

Sumber : Output data primer yang di olah.

\section{Kesimpulam Hipotesis}

Tabel 10. Kesimpulam Hipotesis

\begin{tabular}{|c|l|c|}
\hline & \multicolumn{1}{|c|}{ Hipotesis } & Hasil Pengujian \\
\hline H1 & $\begin{array}{l}\text { Shift kerja berpengaruh positif dan sifnifikan terhadap } \\
\text { kelelahan kerja }\end{array}$ & Terbukti \\
\hline H2 & Shift kerja berpengaruh positif dan signifikan terhadap beban kerja & Terbukti \\
\hline H3 & $\begin{array}{l}\text { Kelelahan kerja berpengaruh positif dan signifikan terhadap } \\
\text { kinerja }\end{array}$ & Tidak Terbukti \\
\hline H4 & Beban kerja berpengaruh positif dan signifikan terhadap kinerja & Tidak Terbukti \\
\hline H5 & Shift kerja berpengaruh positif dan signifikan terhadap kinerja & Tidak Terbukti \\
\hline
\end{tabular}

\section{PENUTUP}

Perbaikan pada sistem manajemen shift kerja pada PT.MI diharapkan mampu mengurangi dampak kelelahan dan beban kerja yang diakibatkan dari penerapan sistem shift kerja. manajemen shift kerja yang baik yang bisa diterapkan oleh PT.MI adalah sebagai berikut :

1. Jika memungkinkan maka waktu shift kerja sebaiknya dibatasi yaitu pembagian waktu tiap 
shift maksimum adalah 8 jam kerja dengan waktu istirahat 1 jam tanpa mengurangi kompensasi dan benefitnya.

2. Jumlah pekerja shift malam sebaiknya dikurangi untuk mengurangi jumlah hari kerja mereka karena menurut penelitian pekerja shift malam mengalami tingkat kelelahan dan beban kerja yang lebih tinggi dibandingkan pekerja shift sore dan shift pagi.

3. Untuk sifat pekerjaan yang harus dilaksanakan secara terus - menerus dengan jumlah pekerja yang terbatas, maka sebaiknya perusahaan menambah jumlah tenaga kerja, memberikan kompensasi/tunjangan khusus dan memberikan waktu istirahat yang cukup.

4. Menyediakan fasilitas kegiatan olahraga untuk menunjang kebutuhan karyawan dalam hal refreshing.

5. Menerapkan jadwal kerja yang fleksibel (flextime) cara ini memungkinkan karyawan untuk menentukan jam kerjanya sendiri. karyawan dibebaskan untuk menentukan apakah mereka ingin memulai jam kerja dengan lebih cepat atau bahkan lebih lambat. Dengan total jam kerja yang sama sesuai dengan ketentuan yang berlaku yaitu delapan jam kerja.

6. Shift kerja berpengaruh secara signifikan terhadap kelelahan kerja dengan nilai 0.563 (56\%).Shift kerja berpengaruh secara signifikan terhadap beban kerja dengan nilai 0.724 (72\%). Kelelahan kerja berpengaruh terhadap kinerja dengan nilai -0.096. Beban kerja berpengaruh terhadap kinerja dengan angka 0.451 . Shift kerja berpengaruh terhadap kinerja dengan angka 0.190 .

7. Variabel yang paling dominan yang dipengaruhi oleh variabel shift kerja adalah variabel beban kerja dengan nilai tertinggi yaitu sebessar 0.724 $(72 \%)$.

\section{DAFTAR PUSTAKA}

Adityawarman, Y., Sanim, B., \& Sinaga, B. M. (2015). Pengaruh Beban Kerja terhadap Kinerja Karyawan PT. Bank Rakyat Indonesia (persero) Tbk Cabang Krekot. Jurnal Manajemen Dan Organisasi, 6(1), 34-44.

Fitria, A. (2003). Pengaruh etika kerja Islam terhadap sikap akuntan dalam perubahan organisasi dengan komitmen organisasi sebagai variabel intervening. Program Pascasarjana Universitas Diponegoro.

Ghozali, I. (2014). Struktural Equation Modeling Metode Alternatif dengan Partial Least Squares (PLS) dilengkapi Software Smartpls 3.0. Xlstat.

Henni, H., Nurina, N., \& Abbas, S. F. (2014). Analisis Pengaruh Shift Kerja Terhadap Beban Kerja Mental Pekerja Dengan Menggunakan Metode Swat (Subjective Workload-assessment Technique). JISI: Jurnal Integrasi Sistem Industri, 1(2).

Setiawan, B. S. A. D. (2017). HUBUNGAN KELELAHAN TERHADAP KINERJA SUPIR DUMP TRUCK PT RAYA BUMI MANDIRI SAMARINDA.

Supomo, T. M. (2014). Shift Kerja Terhadap Kinerja Pegawai Satuan Polisi Pamong Praja Kota Tarakan. Jurnal Ilmiah Psikologi Terapan, 2(1), 75-88. 